\title{
Alcoholización percutánea de quiste hepático simple. Reporte de un caso y revisión de la literatura
}

\author{
Omar Santiago Chungata Peláez \\ Médico Tratante de Cirugía Digestiva, Hospital de Especialidades Abel Gilbert Pontón. Guayaquil, Ecuador.
}

Acta Gastroenterol Latinoam 2020;50(2):210-215

Recibido: 14/07/2019 / Aceptado: 21/08/2019 / Publicado online: 29/06/2020

\section{Resumen}

Con el avance de los métodos complementarios de diagnóstico, la patología quistica no parasitaria hepática se ha transformado en un motivo frecuente de consulta en la práctica diaria. Dentro de la patología quística no parasitaria del higado, se encuentran los quistes serosos simples, la enfermedad poliquistica del adulto y los pseudoquistes. Los quistes simples de higado son formaciones quisticas intrahepáticas, micro o macroscópicas, que tienen su origen en conductos que durante el desarrollo embrionario pierden su comunicación con el árbol biliar, ya sea por obstrucción ductal o por una hiperplasia inflamatoria de los conductos, con la consiguiente retención de líquido en su interior. Presentamos el caso de una paciente con quiste hepático simple, a la cual se le reali-

Correspondencia: Omar Santiago Chungata Peláez Ciudadela Villa Club Etapa Natura Mz 1 Villa 12. Guayaquil, Ecuador Tel.: 04-6015573 / Tel.: 0985338739

Correo electrónico:dr_omar_chungata@hotmail.com za alcoholización del mismo como tratamiento definitivo. Se realiza una revisión bibliográfica, resaltándose las opciones de tratamiento de esta patología.

Palabras clave. Quiste hepático, escleroterapia, percutáneo.

\section{Percutaneous alcoholization of a simple hepatic cyst. A case report and literature review}

\section{Summary}

With the advancement in complementary diagnostic methods, non-parasitic cystic liver disease has become a frequent reason for consultation in daily practice. Within the non-parasitic cystic disease of the liver, are the simple serous cysts, adult polycystic disease and pseudocysts. Simple cysts of the liver are intrahepatic cystic formations micro or macroscopic originating in conduits during embryonic development lose their communication with the biliary tree, either ductal obstruction or inflammatory hyperplastic ducts, thereby retaining liquid inside. We report the case of a patient with simple hepatic cyst which is the same as alcohol addiction takes minimally invasive definitive treatment. A literature review was performed highlighting treatment options for this disease.

Key words. Liver cyst, sclerotherapy, percutaneous. 


\section{Introducción}

El quiste hepático simple se trata de una formación quística secundaria a un desarrollo embriológico anormal, con persistencia de conductos biliares intralobares. Estos quistes poseen un epitelio de células cuboidales o columnares, al parecer de origen biliar, que segregan un líquido seroso, condicionando la formación del quiste. Era una entidad poco frecuente, pero con el avance de los estudios por imágenes su incidencia se ha incrementado. ${ }^{1}$ Suelen ser únicos, aunque en ocasiones pueden presentarse como lesiones múltiples. En ese caso, asientan generalmente en forma unilateral y sobre el lóbulo derecho. Habitualmente son de pequeño tamaño, aunque pueden variar entre 1 y $20 \mathrm{~cm}$. La comunicación con el árbol biliar es excepcional. Se diferencian de la enfermedad poliquística hepática del adulto por la falta de compromiso de otros órganos y la ausencia de antecedentes familiares. ${ }^{2}$ Las mujeres padecen con más frecuencia esta entidad, especialmente entre la cuarta y quinta décadas de la vida, con una proporción mujer a hombre de $4: 1 .^{3}$

Se presenta el caso de una paciente femenina de 45 años de edad, con quiste hepático simple y síntomas dependientes del quiste, a la cual se le realiza primero un drenaje percutáneo del mismo y luego de una semana se introduce alcohol de 70 grados.

\section{Caso clínico}

Paciente femenina de 45 años de edad, con antecedentes quirúrgicos de colecistectomía por colelitiasis hace cinco años. Al momento presenta cuadro clínico de aproximadamente dos años de evolución, con dolor abdominal localizado en epigastrio e hipocondrio derecho, de leve intensidad, acompañado de distensión abdominal y meteorismo. El dolor se intensifica en los últimos dos meses al igual que la distensión abdominal, siendo esta última más intensa después de las comidas. A la exploración física presenta dolor a la palpación profunda a nivel de hipocondrio derecho.

El hemograma mostró glóbulos rojos 4.240.000, hemoglobina 12,2, y hematocrito 36,4; glóbulos blancos 9.400, neutrófilos 45,0\%, linfocitos 32,3\%, ALT 73 ( $\uparrow$ ), AST $39(\uparrow)$, fosfatasa alcalina 76 , bilirrubina total 0,4 , bilirrubina directa 0,1 , bilirrubina indirecta 0.30 , GGT 35, tiempo de protrombina 13,5 , alfa feto proteína normal. La ecografía abdominal informa hígado con incremento difuso de su ecogenicidad, como se observa en la esteatosis hepática moderada, de aspecto heterogéneo dado por la presencia de varios quistes. El de mayor tamaño mide $10 \times 8,5 \mathrm{~cm}$, de paredes regulares con detritus en su interior, tiene un volumen aproximado de $421 \mathrm{cc}$, avascu- lar al doppler color; en el segmento VII observamos dos quistes simples de 2,5 x 2,8 cm y 2,1 x 1,5 cm, en lóbulo izquierdo observamos nódulo sólido hipoecogénico que mide 2,6 x 2,2 cm, no se observa vascularización de la lesión, no dilatación de vías biliares intra ni extrahepáticas., paciente colecistectomizada (Figuras 1 y 2).

Se realizó una tomografía de abdomen que informó hígado de tamaño normal, contornos regulares, con imágenes hipodensas de contornos bien definidos con densidad de agua (8 UH), dispersas en el lóbulo derecho e izquierdo; la de mayor tamaño mide 114 x 94 x 105 mm en el segmento hepático VIII y otras de menor tamaño que miden entre 10 y $20 \mathrm{~mm}$ en el segmento II y VII; no hay dilatación de las vías biliares, ni lesiones de aspecto metastásico, colecistectomía. (Figura 3).

Figura 1 y 2. Ecografía abdominal. Higado de aspecto heterogéneo, dado por la presencia de varios quistes. El de mayor tamaño mide $10 \times 8,5 \mathrm{~cm}$, de paredes regulares con detritus en su interior, tiene un volumen aproximado de $421 \mathrm{cc}$. En el segmento VII observamos dos quistes simples de $2,5 \times 2,8 \mathrm{~cm}$ y $2,1 \times 1,5 \mathrm{~cm}$.
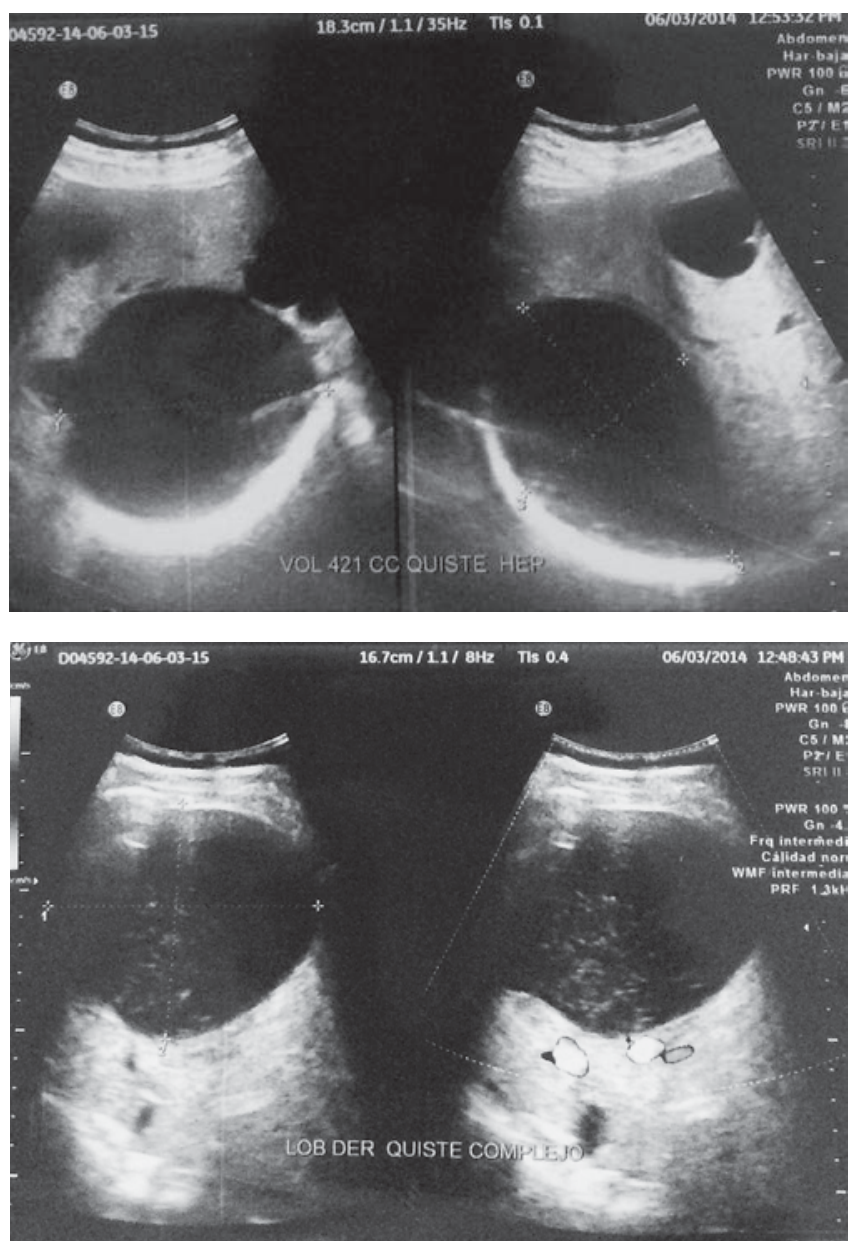
Figura 3. TAC de abdomen. Higado de tamaño normal, contornos regulares, con imágenes hipodensas de contornos bien definidos con densidad de agua (8 UH), dispersas en el lóbulo derecho e izquierdo; la de mayor tamaño mide $114 \times 94 \times 105$ mm en el segmento hepático VIII, y otras de menor tamaño que miden entre 10 y $20 \mathrm{~mm}$ en el segmento II y VII.

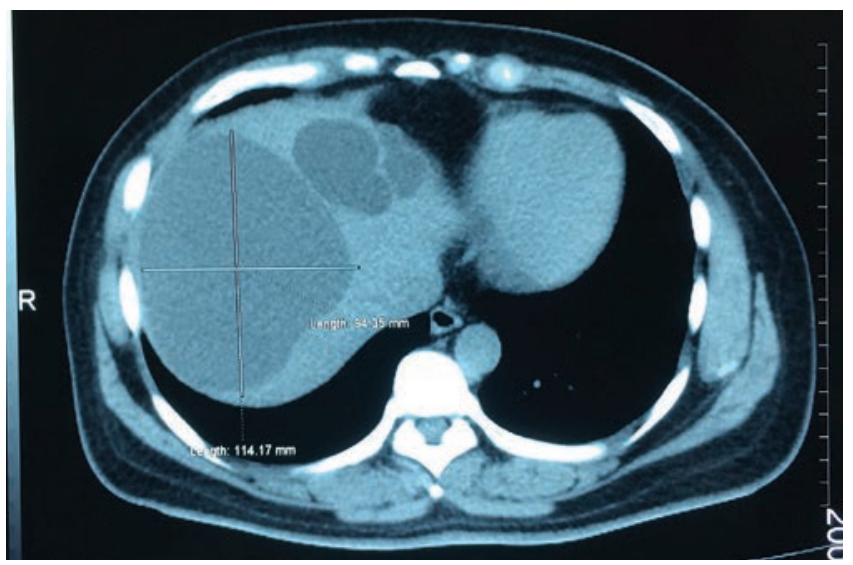

El tratamiento con el que se inicia es el drenaje percutáneo del quiste hepático de mayor tamaño (114 x $94 \mathrm{x}$ $105 \mathrm{~mm}$ en el segmento hepático VIII), utilizando guía tomográfica y técnica de Seldinger; se obtienen $300 \mathrm{cc}$ de líquido seroso y se deja catéter de 8 french a nivel del quiste (Figuras 4 y 5). Una semana después del procedimiento se realiza la escleroterapia (alcoholización) del quiste, procedimiento que se lleva a cabo en quirófano bajo sedación y utilizando ecografía y fluoroscopía: a través del catéter de instila contraste hidrofílico y con ayuda de fluoroscopía se comprueba que el quiste no tiene comunicación con la vía biliar (Figura 6); paso seguido se introduce a través del catéter alcohol de 70 grados durante un minuto y se retira el alcohol. Con ayuda ecográfica se comprueba la indemnidad de la vía biliar; luego de cinco días se retira el catéter. La evolución clínica es favorable, con alivio completo de los síntomas después de la intervención.

Figura 4 y 5. Drenaje percutáneo. Drenaje percutáneo del quiste hepático de mayor tamaño (izquierdo antes y derecho después del drenaje).
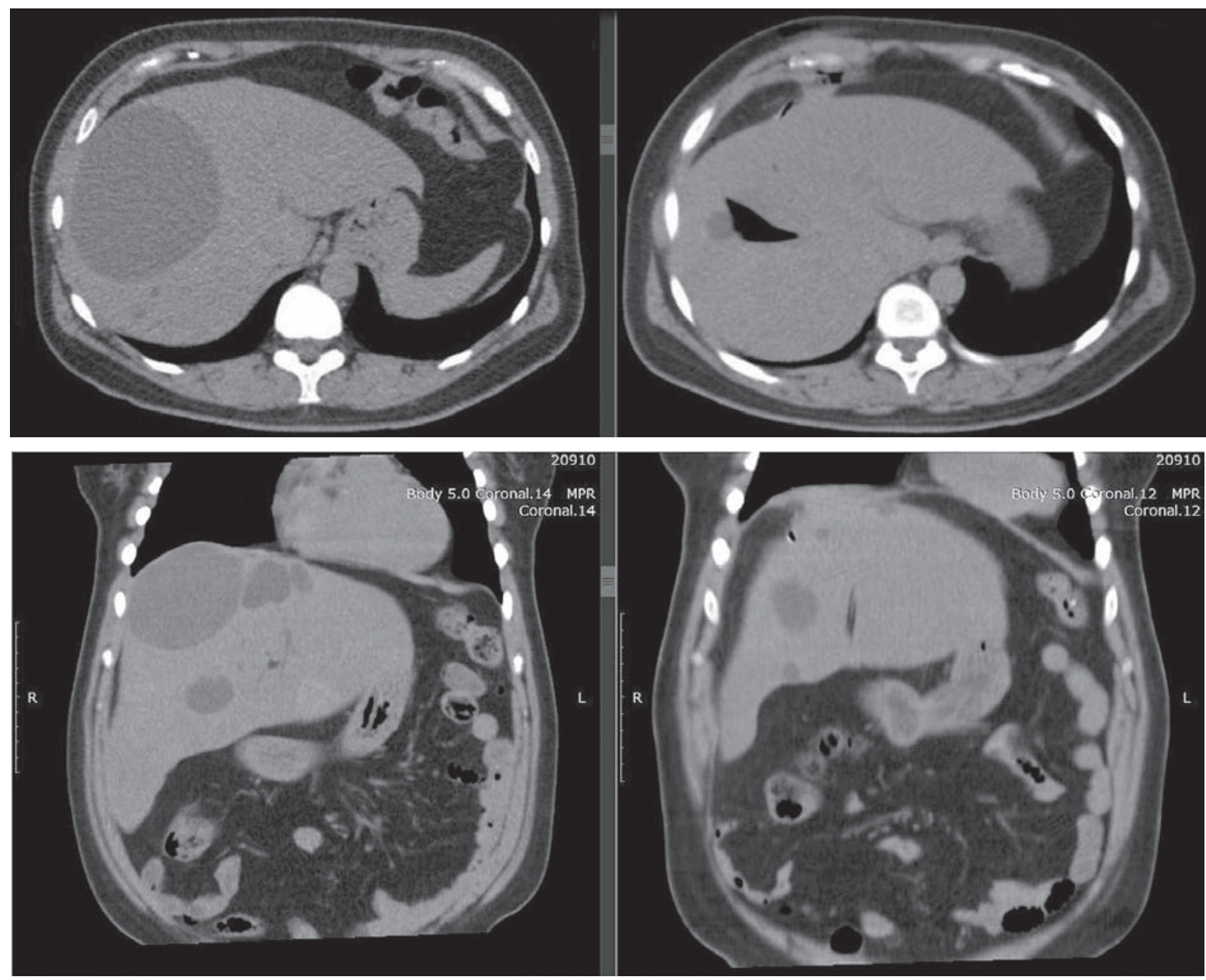
Figura 6. Alcoholización del quiste hepático. A través del catéter se instila contraste hidrofilico y con ayuda de fluoroscopia se comprueba que el quiste no tiene comunicación con la vía biliar.

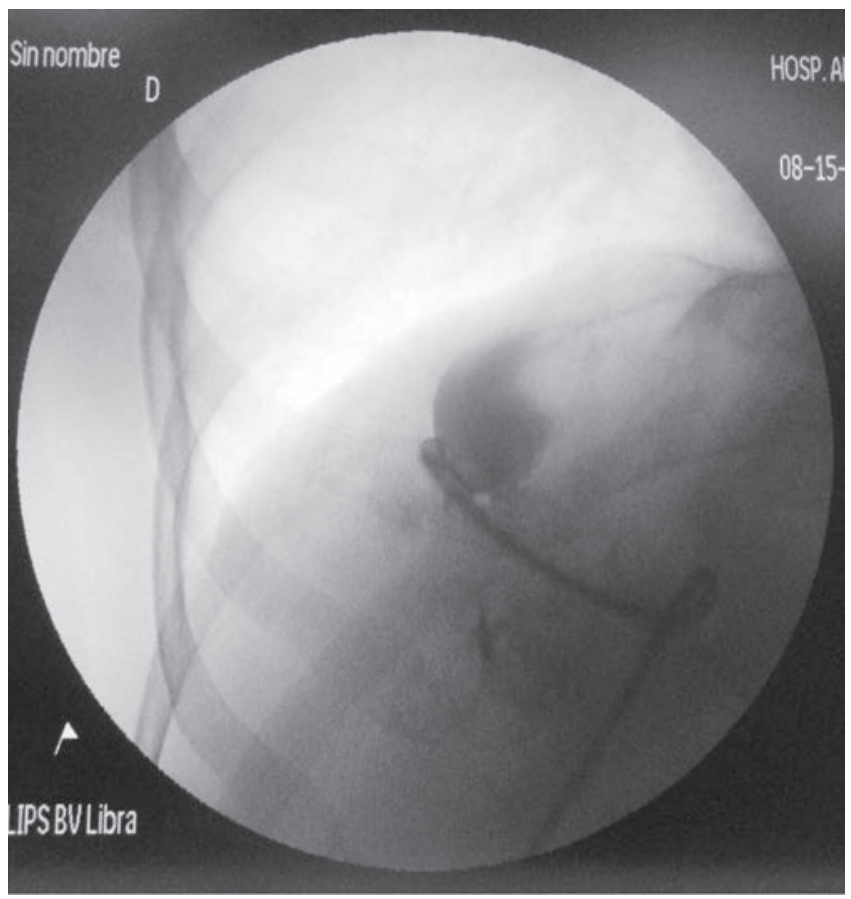

\section{Discusión}

Los quistes hepáticos simples son formaciones de contenido líquido-seroso, rodeadas de un parénquima hepático normal sin comunicación con la vía biliar intrahepática, y su frecuencia en la población adulta es del 2 al 7\%. ${ }^{4}$ Suelen ser asintomáticos y no están asociados con una función hepática anormal. Sin embargo, pueden llegar a ser sintomáticos debido a su expansión. Hasta el $24 \%$ de esos quistes pueden volverse sintomáticos. Los quistes sintomáticos causan, más comúnmente, dolor sordo en el hipocondrio derecho, ictericia o náusea. Los grandes quistes asintomáticos pueden raramente romperse, ocasionando una hemorragia. Generalmente, no son resecados sino más bien observados. ${ }^{5}$ Complicaciones compresivas debido al "efecto de masa del hígado" son: hipertensión portal, edema debido a la compresión de la vena cava, ictericia, arritmia y obstrucción duodenal. La compresión extrínseca gástrica por los quistes hepáticos ha sido poco descrpita. ${ }^{6}$ En forma poco frecuente, los quistes simples pueden presentar complicaciones, siendo las más comunes la hemorragia intraquística y la sobreinfección bacteriana. Se han descripto también fístula duodenal, colestasis por compresión de las vías bi- liares y, excepcionalmente, malignización. La hemorragia intraquística se presenta con un cuadro brusco de dolor abdominal localizado en hipocondrio derecho. Según la magnitud del sangrado, puede estar asociado a signos francos de hipovolemia. Por lo general, son procesos autolimitados porque el aumento de la presión intraquística favorece la hemostasia y detiene el sangrado.

La comunicación de los quistes con la vía biliar es excepcional, y la sobreinfección de estos se produce por lo general por diseminación hemática de gérmenes. En su presentación clínica predomina el cuadro febril y el dolor. En raras ocasiones presentan signos y síntomas de sepsis. $\mathrm{Al}$ examen físico es posible encontrar una masa palpable en las lesiones más voluminosas. Los estudios de laboratorio y función hepática no muestran alteraciones, ya que en esta patología no hay afección parenquimatosa ni deterioro hepatocelular. ${ }^{2}$

El diagnóstico de los quistes hepáticos simples se hace en base a criterios de imagen. ${ }^{1}$ El ultrasonido es la mejor técnica de imagen para el reconocimiento de los quistes simples, que aparecen como una imagen circular u oval, anecoica de bordes lisos y refuerzo acústico posterior y sin tabiques. Otros estudios de imagen, incluida la tomografía computarizada, no se requieren rutinariamente y muestran imágenes redondeadas y con densidad de agua. ${ }^{10}$ En las imágenes de resonancia magnética nuclear, los quistes simples muestran baja intensidad de señal homogénea en las imágenes potenciadas en T1 y alta intensidad de señal en las imágenes potenciadas en T2, sin componentes de tejidos blandos o septos internos. ${ }^{7}$

La gran mayoría de los quistes hepáticos simples no requieren tratamiento. Los quistes grandes (diámetro de 4 cm o más) pueden ser seguidos con estudios de imágenes repetidos. Si el quiste se mantiene sin cambios durante dos años, la monitorización puede ser interrumpida. Los quistes sintomáticos o en crecimiento requieren consideración de diagnósticos alternativos, incluyendo cistoadenoma, cistadenocarcinoma y metástasis hepáticas. Cabe destacar que la atribución de los síntomas a los quistes simples debe realizarse con precaución después de excluir diagnósticos diferenciales. El dolor abdominal en epigástrico o en el cuadrante superior derecho provocado por la alimentación puede indicar un cólico biliar, si los cálculos biliares están presentes. Pacientes seleccionados pueden someterse a endoscopía digestiva alta para diagnosticar esofagitis erosiva o úlcera péptica. La monitorización del $\mathrm{pH}$ esofágico puede confirmar el diagnóstico de reflujo gastroesofágico. Si los síntomas fluctúan concomitantemente con los cambios en la frecuencia o 
forma de las deposiciones, debe sospecharse un diagnóstico de síndrome de intestino irritable. Por último, un diagnóstico de dispepsia no ulcerosa puede ser atribuido en pacientes con endoscopía alta sin complicaciones que han continuado con dolor abdominal superior intenso, posiblemente en asociación con náuseas y vómitos. Si los diagnósticos anteriores pueden excluirse con confianza, puede llevarse a cabo el tratamiento del quiste hepático grande sintomático. ${ }^{9}$

En los pacientes sintomáticos que requieren intervención, ya sea la escleroterapia o destechamiento quirúrgico, debe descartarse quiste hidatídico en todos los casos antes de la operación, por serología y por la historia del paciente de viajes recientes a zonas endémicas. ${ }^{8}$

Tratamiento quirúrgico convencional: la cirugía consiste en el destechamiento de la pared emergente del quiste, resecando la mayor cantidad de pared posible. Esta técnica ha sido descripta por Lin en el año 1968, y numerosas series han demostrado su efectividad. El destechamiento comienza en el caso de grandes lesiones con la aspiración del contenido para un mejor manejo del hígado al reducirse el tamaño de la lesión. Puede realizarse con electrobisturí monopolar como único medio para el control de la hemostasia, aunque en el caso de paredes gruesas o vascularizadas, el bisturí ultrasónico puede ser de gran utilidad. Al efectuar esta maniobra, debe prestarse especial cuidado en no resecar parénquima hepático comprometido por la expansión quística, que puede contener en su interior canalículos biliares condicionantes de bilirragia en el postoperatorio. El objetivo es permitir que la pared remanente del quiste quede comunicada con el peritoneo, ya que el epitelio quístico sigue produciendo líquido seroso.

Una de las principales causas de recidiva precoz es la falla en esta comunicación, producto del contacto del borde destechado del quiste con estructuras adyacentes (el diafragma, principalmente) con la consiguiente acumulación de líquido. Algunos autores preconizan el relleno de la cavidad remanente con epiplón, a fin de lograr un drenaje más efectivo de la secreción del epitelio. Dado que la comunicación del quiste con el árbol biliar es excepcional, no es necesaria la utilización rutinaria de la colangiografía.

Abordaje laparoscópico: en informes anteriores, el abordaje laparoscópico de los quistes localizados en los segmentos VI, VII y VIII se consideraba una contraindicación para este procedimiento no invasivo. Sin embargo, de acuerdo con un estudio reciente, la ubicación del quiste no debe ser más una contraindicación para un procedimiento laparoscópico. Durante el procedimiento quirúrgico, el contenido del quiste debe ser aspirado para determinar si la comunicación con el sistema biliar intrahepático está presente. Los quistes hepáticos pueden mostrar septos internos y/o nódulos murales en los estudios de imagen después de una hemorragia intraquística y, por lo tanto, se aconseja la resección si el quiste neoplásico no puede descartarse. ${ }^{10}$

La escleroterapia percutánea es de primera elección debido a la eficacia de esta técnica mínimamente invasiva.10 La eficacia clínica de la escleroterapia percutánea con etanol (alcoholización) es muy alta con resultados satisfactorios de hasta un $95 \% .{ }^{11}$ Consiste en la destrucción del revestimiento epitelial de la superficie interior de la pared para interrumpir la secreción de fluido intraquística. Bajo anestesia general, se introduce un catéter de drenaje mediante la técnica de Seldinger y bajo control ecográfico, seguida de la inyección de contraste hidrosoluble para descartar la comunicación con la vía biliar adyacente o en la cavidad peritoneal. ${ }^{8}$ Agentes esclerosantes incluyen etanol, hidrocloruro de minociclina ${ }^{8,12}$ y oleato de etanolamina. La cantidad de inyección de alcohol es limitada debido al riesgo de intoxicación por alcohol. La solución se aspira a continuación, antes de que se retire el catéter. El tamaño del quiste no juega un papel en la cantidad de agente esclerosante dado, porque después del colapso del quiste el esclerosante entrará en contacto con la pared interna de este. Contraindicaciones de la escleroterapia incluyen sangrado intraquístico y fístula entre el quiste y el árbol biliar o el peritoneo. La eficacia óptima se puede ver hasta un año después de la escleroterapia. ${ }^{8}$ Cabe destacar que la escleroterapia solo es aplicable cuando el sangrado, la hidatidosis, procesos neoplásicos y la comunicación con el árbol biliar se han descartado. ${ }^{12}$

\section{Conclusión}

La alcoholización percutánea, como procedimiento mínimamente invasivo, es una técnica eficaz en el tratamiento del quiste hepático simple, con resultados satisfactorios de hasta un $95 \%$ de los casos usando el etanol (alcohol de 70 grados) como sustancia esclerosante, como muestra el caso de nuestra paciente. Debe tenerse una certeza diagnóstica previo al procedimiento, con base en los estudios de imágenes y de laboratorio señalados anteriormente, descartando todos los diagnósticos diferenciales posibles. Es en el momento del procedimiento cuando se realizan los últimos dos estudios diagnósticos: el primero consiste en extraer el contenido del quiste, 
el cual debe tener características de líquido seroso, y el segundo previo a la escleroterapia se introduce contraste hidrofílico en el quiste y se realiza una fluoroscopía, con lo cual se comprueba que el quiste no tenga comunicación con la vía biliar.

\section{Referencias}

1. Parrilla P, Landa J. Cirugía Asociación Española de Cirugía. 2da edición, Editorial Médica Panamericana. Madrid-España 2010: 645-649.

2. Galindo F. Enciclopedia de Cirugía Digestiva, Sociedad Argentina de Cirugía Digestiva, Argentina 2009; Volumen IV-409.

3. Castillo J, Carrillo J, León G. Quiste Hepático Gigante Simple, Manejo con Cirugía de Mínima Invasión. Acta Médica Grupo Ángeles 2012; 10 (3): 137-139. Disponible en: www.medigraphic.com/actamedica.

4. Gómez J, González N. Quiste Hepático Simple Gigante como Causa de Disnea en paciente de 93 años. Anales de Medicina Interna, Madrid 2007; 24 (3).

5. Gambling T, Holloway S, Heckman J. Resección Laparoscópica de Quistes Hepáticos Benignos: un nuevo estándar, Am Coll Surg 2008; 207 (5): 731-736.
6. Zippi M, Bruni A, Scevola T. Large symptomatic simple hepatic cyst with gastric compression treated with percutaneous drainage, Clin Ter 2014; 165 (2): 170-173.

7. Adib R, Caitlin C, Urvi F. Alcohol sclerosis of a giant liver cyst following failed deroofings. The Journal of Radiology Case Reports 2011; 5 (2): 19-22.

8. Macedo F. Current management of noninfectious hepatic cystic lesions: A review of the literature. Mundial Journal Hepatology 2013; 5 (9): 462-469.

9. Blonski W, Campbell M. Successful aspiration and ethanol sclerosis of a large, symptomatic, simple liver cyst: Case presentation and review of the literature. World Journal of Gastroenterology 2006; 12 (18): 2949-2954.

10. Erdogan D, Delden O, Rauws E. Results of percutaneous sclerotherapy and surgical treatment in patients with symptomatic simple liver cysts and polycystic liver disease. World Journal of Gastroenterology 2007; 13 (22): 3095-3100.

11. Benzimra J, Ronot M, Fuks D. Hepatic Cysts treated with percutaneous etanol sclerotherapy: time to extend the indications to haemorrhagic cysts and polycystic liver disease. Eu Radiol 2014; 24 (5): 1030-1038.

12. Choi C, Kim Y, Roh Y. Management of giant hepatic cysts in the laparoscopic era. Journal of the Korean Surgical Society 2013; 85 (3): 116-122. 